\title{
Selective Growth Arrest and Phenotypic Reversion of Prostate Cancer Cells In Vitro by Nontoxic Pharmacological Concentrations of Phenylacetate
}

\author{
Dvorit Samid, Sonsoles Shack, and Charles E. Myers \\ Clinical Pharmacology Branch, Division of Cancer Treatment, National Cancer Institute, Bethesda, Maryland 20892
}

\begin{abstract}
Differentiation therapy may provide an alternative for treatment of cancers that do not respond to cytotoxic chemotherapy or hormonal manipulations. This hypothesis led us to evaluate the effect of a nontoxic differentiation inducer, sodium phenylacetate (NaPA), on hormone-refractory prostate cancer, the second most common cause of cancer deaths in men. NaPA treatment of androgen-independent PC3 and DU145 prostate cell lines, like that of hormone-responsive LNCaP cultures, resulted in dose-dependent inhibition of cell proliferation. Similar treatments were not significantly inhibitory to replicating normal endothelial cells and skin fibroblasts. In addition to the selective cytostatic effect, NaPA induced reversion of the prostatic cells to a nonmalignant phenotype, evidenced by their reduced invasiveness and loss of tumorigenicity in athymic mice. Phenotypic reversion was accompanied by alterations in gene expression, including selective reduction in tumor growth factor- $\beta 2$ mRNA levels and increased amounts of class I major histocompatibility complex HLA transcripts. Furthermore, there was a decrease in tumor-associated proteolysis mediated by urokinase plasminogen activator, a molecular marker of disease progression in humans. When tumor cells were treated with NaPA together with suramin, a drug with demonstrable activity in patients, there was complete abrogation of cell growth under conditions in which each treatment alone produced only a partial effect. The in vitro antineoplastic activity was observed with drug concentrations that have been achieved in humans with no significant toxicities, suggesting that PA, used alone or in combination with other antitumor agents, warrants evaluation in the treatment of advanced prostatic cancer. (J. Clin. Invest. 1993.91:2288-2295.) Key words: athymic mice $\bullet$ human histocompatibility leukocyte antigens $\bullet$ suramin • tumor grow factor- $\beta$ • tumor invasion • urokinase
\end{abstract}

\section{Introduction}

Prostate carcinoma is second only to lung cancer as a cause of cancer deaths in men (1). Current treatment protocols for this disease rely upon androgen deprivation; however, despite ini-

Address reprint requests to Dr. Dvorit Samid, Clinical Pharmacology Branch, National Cancer Institute, Building 10, Room 12C103, 9000 Rockville Pike, Bethesda, MD 20892.

Received for publication 2 September 1992 and in revised form 6 January 1993.

The Journal of Clinical Investigation, Inc.

Volume 91, May 1993, 2288-2295 tial high response rates, patients with metastatic prostate cancer develop hormone-refractory disease that results in a fatal outcome (2). Conventional cytotoxic chemotherapy is designed to be selectively toxic to cells based upon rate of proliferation or ability to repair DNA damage. The general consensus is that such agents are of marginal value in the treatment of hormone-refractory prostate cancer in as much as the median survival of such patients is only 7-8 mo (3). Recently, objective responses have been documented in patients treated with suramin, a polysulfonated naphthylurea (4): this drug caused pain relief, reduced serum levels of prostatic specific antigen, and brought about tumor regression in patients with measurable soft tissue disease (5). Suramin appears to exert its antitumor effect by blocking autocrine growth factors and altering patterns of tyrosine phosphorylation $(4,6)$. These findings suggest that treatment of prostate cancer might best be approached through attack upon the vulnerable control points of malignant transformation rather than through such properties as proliferation rate or DNA repair.

Differentiation therapy is an attractive alternative in cases where cytotoxic therapy is not effective. The underlying hypothesis is that neoplastic transformation results from defects in cellular differentiation; inducing tumors to differentiate would result in reversal of malignancy (7-9). Several differentiation inducing agents have been used in treatment of patients with hematopoietic and solid tumors, including retinoids, sodium butyrate, interferons, 5-azacytidine, and hexamethylene bisacetamide $(7,10-12)$. Clinical applications of some of these agents have been limited by unacceptable toxicities including potential carcinogenesis, or inability to achieve and sustain effective plasma concentrations. However, the management of promyelocytic leukemia has been revolutionized by the shift from combination chemotherapy to the use of all-trans-retinoic acid (12), indicating the potential value of this approach.

Our laboratory has recently identified a new nontoxic differentiation inducer, sodium phenylacetate $(\mathrm{NaPA})^{1}(13)$. Experimental data indicate that phenylacetate can promote maturation of various human leukemic cell lines and immortalized mouse mesenchymal cultures at nontoxic concentrations readily achievable in humans (13-16). Cells treated in culture exhibited new patterns of gene expression $(13,14)$, some of which were also seen in treated patients (17). The profound effect of PA on cellular and molecular biology is not limited to vertebrate cells. This common metabolite of phenylalanine has been implicated in growth control of such divergent organisms

1. Abbreviations used in this paper: DON, 6-diazo-5-oxo-L-norleucine; NaPA, sodium phenylacetate; PAG, phenylacetylglutamine; uPA, urokinase plasminogen activator. 
as bacteria (18), fungi (19), and plants (20). PA thus provides one more example of a well-established phenomenon of small, simple molecules having complex physiological regulatory effects with potential therapeutic applications ( nitrates used as vasodilators to treat angina is another example; see reference 21 ).

The finding that PA can induce differentiation of human malignant cells led us to examine the activity in prostate cancer. PA was of particular interest considering that, in addition to affecting tumor biology in vitro, this agent is capable of binding to, and depleting circulating glutamine in humans (22). Prostatic cancer cells, like many other tumor types, show marked dependence on circulating glutamine for energy metabolism as well as for synthesis of nucleic acids and proteins (23, 24 ). In contrast to normal cells, tumor cells typically operate at limiting levels of glutamine availability owing to increased utilization and reduced production, making glutamine a desirable therapeutic target (23). Tumor responses were obtained with such glutamine antimetabolites as 6-diazo-5-oxo-L-norleucine (DON) and $\mathrm{L}(\alpha \mathrm{S} .5 \mathrm{~S}) \alpha$-amino-3-chloro-4,5-dihydro-5-isoxazoleacetic acid (acivicin), and the glutamine-depleting enzyme glutaminase; however, the clinical usefulness of these agents has been limited by their adverse effects (25-27). By contrast, clinical experience with NaPA, used in treatment of hyperammonemia associated with inborn errors of urea synthesis, indicate that high drug doses $(250-550 \mathrm{mg} / \mathrm{kg}$ per d) can be administered orally or intravenously over prolonged periods with no significant toxicities $(15,16)$.

To investigate the effect of phenylacetate on metastatic prostate carcinoma, we have used two androgen-independent human prostatic cell lines, PC3 and DU145, established from metastases to bone and brain, respectively $(28,29)$, and an androgen-sensitive line, $\mathrm{LNCaP}(30)$, originally obtained from an aspirate of a subcutaneous supraclavicular lymph node metastasis. We show here that PA, used at pharmacological nontoxic doses, can suppress the malignant phenotype of cultured prostatic cells, and enhance the efficacy of suramin, an anticancer drug of clinical interest.

\section{Methods}

Cell cultures and reagents. Prostatic cell line PC3, DU145, and LNCaP were purchased from the American Type Culture Collection (Rockville, MD), and maintained in RPMI 1640 supplemented with $10 \%$ heat-inactivated fetal calf serum (Gibco Laboratories, Grand Island, $\mathrm{NY}$ ), antibiotics, and $2 \mathrm{mM}$ L-glutamine, unless otherwise specified. Human umbilical vein endothelial cells, isolated from freshly obtained cords, were kindly provided by D. Grant and H. Kleinman (National Institutes of Health, Bethesda, MD) and maintained in culture as described (31). The diploid human foreskin FS4 fibroblasts (American Type Culture Collection) were grown in DME with the above supplements, unless otherwise indicated. Both RPMI and DME were purchased free of glutamine. For glutamine-starvation studies, the fetal calf serum was stored at $4^{\circ} \mathrm{C}$ for 2-4 wk before use to reduce its glutamine levels to $<0.6 \mathrm{mM}(13,14)$. Because the serum concentration in the growth medium was $10 \%$, the final concentration of glutamine did not exceed $0.06 \mathrm{mM}$ if glutamine was not supplemented. Phenylacetic acid (Sigma Chemical Co., St. Louis, MO) was dissolved in distilled water, brought to $\mathrm{pH} 7.0$ by the addition of $\mathrm{NaOH}$, and stored in aliquots at $-20^{\circ} \mathrm{C}$ till used. Phenylacetate glutamine (PAG) was a gift from S. Brusilow, Johns Hopkins University, Baltimore, MD. DON and acivicin were purchased from Sigma Chemical Co. Suramin was from Mobay Chemical Corp. (New York).

Quantitation of cell number, viability, and DNA synthesis. Growth rates were determined by cell enumeration using a hemocytometer after detachment with trypsin/EDTA, and by thymidine incorpora- tion into DNA. For analysis of thymidine incorporation, cells were labeled with $1 \mu \mathrm{Ci} / \mathrm{ml} \mathrm{[}{ }^{3} \mathrm{H}$ ] thymidine $(6.7 \mathrm{Ci} / \mathrm{ml}$, Dupont-New England Nuclear, Boston, MA) for $2 \mathrm{~h}$, and the TCA-precipitable radioactivity determined using a liquid scintillation counter. Cell viability was assessed by trypan blue exclusion.

Invasion through matrigel. The ability of cells to degrade and cross tissue barriers was assessed by two in vitro invasion assays that utilize matrigel, a reconstituted basement membrane (Collaborative Research, Walthan, MA). Cells were first treated in tissue culture plastic dishes for 4-6 d. For qualitative evaluation of cell behavior, $5 \times 10^{4}$ cells were replated onto 16-mm dishes (Costar, Cambridge, MA), which were previously coated with $250 \mu \mathrm{l}$ of matrigel $10 \mathrm{mg} / \mathrm{ml}$. Drugs were either added to the dishes or omitted in order to determine the reversibility of effect. The netlike formation characteristic of invasive cells occurred within $12 \mathrm{~h}$; invasion into the matrigel was evident after 6-9 d. Quantitative analysis of invasion was performed as previously described (32), using a modified Boyden chamber containing a matrigel-coated filter, with FS4-conditioned medium as chemoattractant. Briefly, cells pretreated for 4-7 d in culture were placed onto the upper chamber at $3 \times 10^{4}$ cells/well, and incubated at $37^{\circ} \mathrm{C}$ for $16-20 \mathrm{~h}$. Filters were then removed, fixed with methanol, and stained with Giemsa. Cells attached to the upper side of membranes were removed, and the number of invading cells found on the inner side was determined by microscopy.

Tumor formation in athymic mice. Cells were injected subcutaneously $\left(5 \times 10^{5}\right.$ cells per site) into 4-6-wk-old female athymic nude mice (Division of Cancer Treatment, National Cancer Institute Animal Program, Frederick Cancer Research Facility). The number, size, and weight of tumors were recorded after $8 \mathrm{wk}$. For histological examination, tumors were excised, fixed in Bouin's solution (picric acid/ $37 \%$ formaldehyde/glacial acetic acid, 15:5:1 vol/vol/vol), and stained with hematoxylin and eosin.

Measurement of urokinase plasminogen activator (UPA) activity. uPA activity of intact cells was determined by the degradation of fibronectin in the presence of plasminogen, with minor modifications to established procedures (33). Cells in logarithmic phase of growth were detached with trypsin/EDTA and incubated in growth medium for $1 \mathrm{~h}$ at room temperature to allow recovery of surface proteins. All traces of serum were then removed by washing the cells with serum-free DME. Aliquots of $200 \mu \mathrm{l}$ of the cell suspension $\left(4 \times 10^{6} \mathrm{cells} / \mathrm{ml}\right.$ in serumfree DME) were added to a 96-multiwell plate precoated with human ${ }^{125}$ I-fibronectin (ICN, Irvine, CA ), and containing $50 \mu$ l of DME with or without $1 \mathrm{U} / \mathrm{ml}$ of porcine plasminogen (Sigma Chemical Co.). Human uPA (Sigma Chemical Co.) was used to obtain a standard curve. The plates were incubated at $37^{\circ} \mathrm{C}$ in $5 \% \mathrm{CO}_{2}$ and the amount of soluble, degraded fibronectin was measured at 30,60 , and $90 \mathrm{~min}$ thereafter by removing $50-\mu \mathrm{l}$ aliquots and measuring the radioactivity in a gamma counter.

Northern blot analysis. Total cytoplasmic RNA was extracted from treated and control cells by the Nonidet P-40 lysis method (34). RNA aliquots ( $20 \mu \mathrm{g}$ per lane) were electrophoresed through $1 \%$ agarose/ formaldehyde gels and blotted onto nylon membranes (Nytran, Schleicher \& Schuell Inc., Keene, NH). RNA transfer, hybridization with ${ }^{32} \mathrm{P}$-labeled specific probes, and autoradiography (XAR5 X-ray film, Eastman Kodak Co., Rochester, NY) were performed according to standard procedures (34). The probes, HLA-A3 HindIII/EcoRI DNA fragment (35), 1.2-kb rat TGF- $\beta 1$ cDNA (36), and 1.2-kb simian TGF- $\beta 2$ cDNA (37), were labeled with [ $\left.{ }^{32} \mathrm{P}\right] \mathrm{dCTP}$ (New England Nuclear) using random primed DNA labeling kit (Boehringer Mannheim, GmbH, Mannheim, FRG).

\section{Results}

Effect of NaPA on cell growth and morphology. As shown in Fig. 1, NaPA treatment of PC3, DU145, and LNCaP cells resulted in dose-dependent growth arrest. The concentrations causing 50\% inhibition $\left(\mathrm{IC}_{50}\right), 3-6 \mathrm{mM}$, have been achieved in 


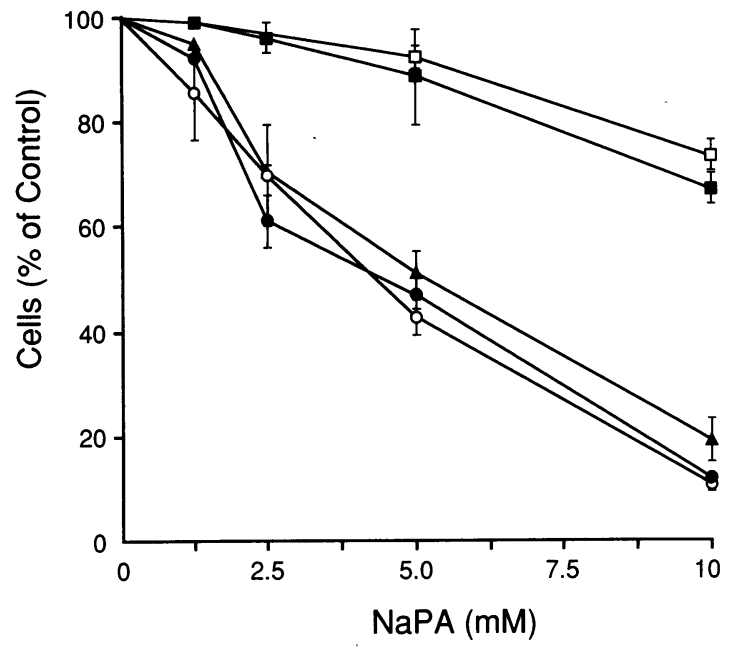

Figure 1. Effect of NaPA on cell proliferation. Cells in logarithmic phase of growth were subjected to continuous treatment with NaPA Results (mean $\pm \mathrm{SD}, n=4$ ) were recorded $4 \mathrm{~d}$ later. In all cases, cell viability was over 95\%. ^, PC3; •, DU145; O, LNCaP; •, FS4; $\square$, human endothelial cells.

human plasma with no significant toxicities $(15,16)$. The decline in proliferation was accompanied by similarly reduced DNA synthesis (not shown), by cell swelling, and by accumulation of lipids that stained positive with Oil-Red O (Fig. 2). In contrast to the tumor cells, significantly higher drug concentrations were needed to affect the growth rate of actively replicating normal human FS4 skin fibroblasts and endothelial cells ( $\mathrm{IC}_{50} 12-15 \mathrm{mM}$ ). Cell viability was over $95 \%$ in both the normal and tumor cultures treated for $4 \mathrm{~d}$ with NaPA doses as high as $20 \mathrm{mM}$. Drug selectivity, observed with cells cultured in their respective optimal growth medium (see Methods), was confirmed under conditions in which both normal FS4 and malignant DU145 cells were cultured in DME, a suboptimal medium for the prostatic tumor cells (data not shown).

Susceptibility of prostatic tumor cells to glutamine depletion. In humans, NaPA causes depletion of circulating glutamine due to conjugation of the amino acid to form PAG, an enzymatic reaction known to take place in the liver and kidney (22). The in vivo reduction in plasma glutamine levels was mimicked in vitro by culturing cells in the presence of lowered glutamine concentrations. Glutamine deprivation inhibited proliferation of the prostatic cell lines, although to a different degree. When glutamine levels were dropped to $0.2 \mathrm{mM}$ (i.e., two- to threefold reduction below physiological levels, similar to that seen in urea cycle patients treated with NaPA [16]), DU145, PC3, and LNCaP cell numbers were $70 \%, 28 \%$, and $66 \%$ (mean values) lowered compared to untreated controls, as determined after 4-6 d of continuous glutamine starvation. Addition of NaPA $5 \mathrm{mM}$ to the glutamine-depleted medium further augmented the cytostatic effect up to $82.5 \%$ (DU145), $67 \%$ ( $\mathrm{PC} 3$ ), and $87 \%$ ( $\mathrm{LNCaP}$ ). In contrast to the prostatic tumor cells, growth of normal skin fibroblast and endothelial cells was not affected even when glutamine levels were lowered further to $0.1 \mathrm{mM}$, a condition that led to cell death in DU145 cultures. Other antiglutamine therapeutics, DON $10 \mu \mathrm{g} / \mathrm{ml}$ and acivicin $100 \mu \mathrm{g} / \mathrm{ml}$, caused $\sim 50 \%$ reduction in PC3 cell numbers after $4 \mathrm{~d}$ of treatment. However, in agreement with previous reports (13), such treatments were significantly toxic to both tumor and normal cells (viability below $70 \%$ ).
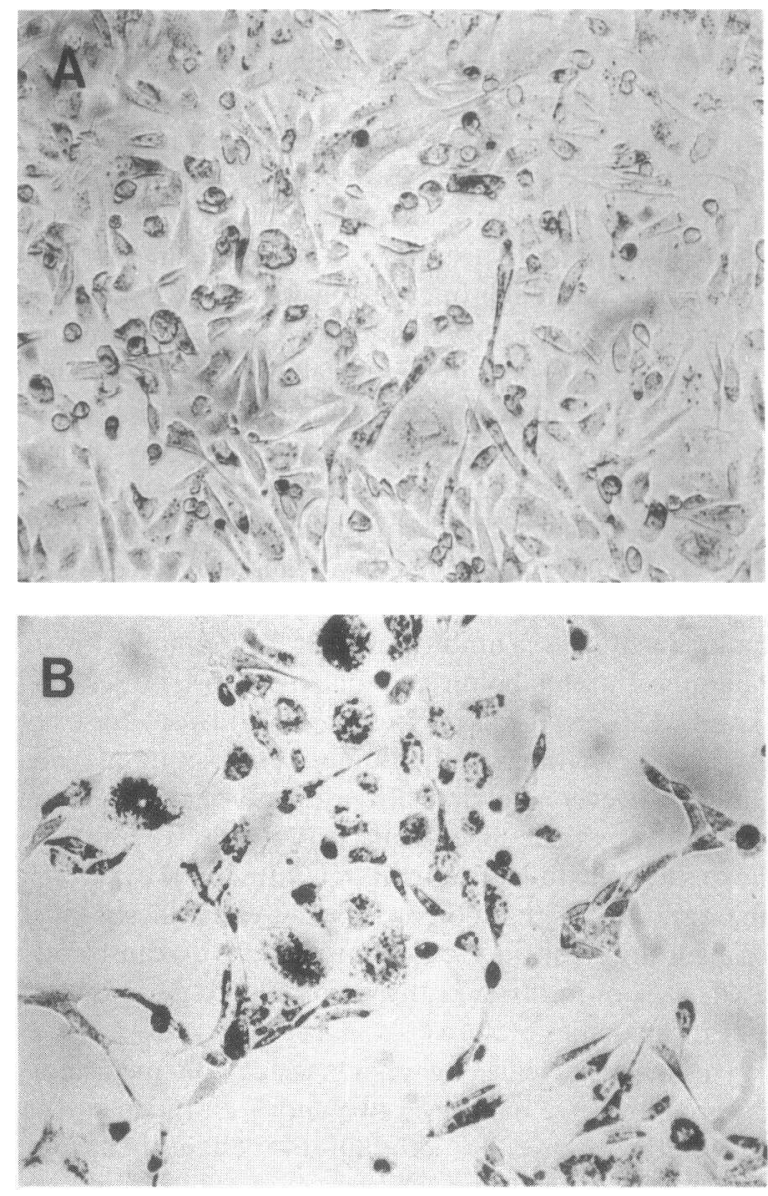

Figure 2. Morphological changes induced by NaPA. PC3 cells treated with $5 \mathrm{mM} \mathrm{NaPA}$ for $6 \mathrm{~d}(B)$ were fixed and stained with Oil-Red O. A 6-d untreated control culture $(A)$ is shown for comparison. Differences in cell densities reflect on the cytostatic effect of NaPA. Light microscopy $(\times 100)$ shows NaPA-treated cells to have extended cytoplasms filled with lipids. Lipid accumulation was associated with treatment and independent of cell density (not shown).

Inhibition by NaPA of prostate cell invasiveness and tumorigenicity. PC 3 cells, which are invasive in vitro and metastatic in recipient athymic mice $(32,38,39)$, were used to further examine the effect of $\mathrm{NaPA}$ on the malignant phenotype. The ability of PC 3 cells to degrade and cross tissue barriers was assessed by two in vitro invasion assays that utilize matrigel, a reconstituted basement membrane. Fig. 3 provides a summary of a quantitative analysis, using a modified Boyden chamber with a matrigel-coated filter (32) and FS4-conditioned medium as chemoattractant. After $4 \mathrm{~d}$ of continuous treatment with NaPA $5 \mathrm{mM}$, there was $88 \pm 3 \%$ inhibition of PC 3 cell invasion. This finding, indicating loss of malignant properties after treatment, was substantiated by the behavior of cells grown in matrigelcoated tissue culture dishes. In agreement with previous observations (32), the malignant PC 3 cells developed characteristic netlike structures, and eventually degraded the extracellular matrix components (Fig. 4). In marked contrast, NaPAtreated PC3 formed small noninvasive colonies on top of the matrigel, resembling the growth pattern of normal human FS4 fibroblasts. Glutamine starvation alone did not produce such phenotypic changes. Results of the in vitro invasion assays have previously been shown to correlate with cell tumorigenic- 


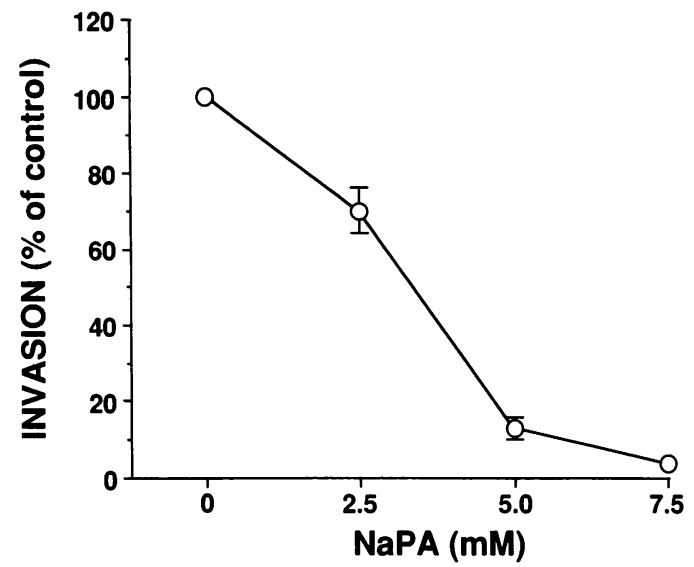

Figure 3. Quantitative analysis of tumor cell invasion. The ability of cells to degrade and cross tissue barriers was assessed by an in vitro invasion assay that utilizes modified Boyden chambers containing matrigel-coated filters. PC 3 cells pretreated for 4-7 d in culture were placed onto the upper chamber and incubated at $37^{\circ} \mathrm{C}$ for $16-20 \mathrm{~h}$. The number of invading cells found on the inner side was determined as described in Methods. Data represent means $\pm \operatorname{SD}(n=12)$.

ity and invasiveness in vivo (32). In agreement, PC3 cells treated with $\mathrm{NaPA}$ for $1 \mathrm{wk}$ in culture, in contrast to untreated cells or those treated with PAG, failed to form tumors when transplanted subcutaneously into athymic mice (Table I). While control animals developed highly invasive and angiogenic tumors, only one of the seven mice injected with NaPAtreated PC3 formed a slow growing tumor, which had poor supporting vasculature and showed no evidence for invasion of surrounding tissues (not shown).

Molecular traits of phenotypic reversion. The malignant prostatic cell lines exhibit numerous abnormalities in gene expression, including increased production of autocrine tumor growth factor- $\beta$ (TGF- $\beta$ ) and elevated activity of urokinase plasminogen activator (uPA). Members of the TGF- $\beta$ family have been implicated in tumor growth control, angiogenesis, and immunosuppression $(40,41)$. uPA is a serine protease involved in degradation of extracellular stroma and basal lamina structures, with the potential to facilitate tumor invasion and metastasis $(38,39,42,43)$. It was of interest, therefore, to examine the effect of NaPA on TGF- $\beta$ and uPA expression in the prostatic tumor cells. Northern blot analysis of PC 3 after 72 $\mathrm{h}$ treatment revealed a decrease in TGF- $\beta 2$ mRNA levels; the effect was specific for TGF- $\beta 2$ as there was no change in the expression of TGF- $\beta 1$ (Fig. 5). The decrease in TGF- $\beta 2$ was accompanied by approximately a twofold increase in the levels of HLA-A3 mRNA (Fig. 5), as previously observed in treated human leukemic HL-60 cells (13).

Preliminary analysis of uPA transcript levels showed no significant change after NaPA treatment (not shown). There was, however, a reduction in cell-surface uPA activity. In agreement with previous reports, the hormone-refractory malignant PC 3 and DU145 cells, but not the more indolent hormone-responsive LNCaP, displayed high cell-bound uPA activity ( Table II $[38,39])$. Because the parental PC 3 cultures are composed of highly heterogenous cell populations with respect to uPA production, we established more homogeneous subclones by limiting dilutions and single-cell cloning. A subclone designated PC3-1, which resembled the parental PC3 cells in its invasive capacity and surface-localized uPA activity $(2.2 \pm 0.3$ $\times 10^{-6}$ Plau units per cell), was chosen for further studies. After $3 \mathrm{~d}$ of treatment of PC3-1 with NaPA $5 \mathrm{mM}$ there was over $50 \%$ reduction in cell-associated uPA activity; the effect was dose-dependent and reversible upon cessation of treatment. Similar results were obtained with DU145 cells. Assay specificity was confirmed by the fact that pretreatment of cells with neutralizing anti-human uPA monoclonal antibodies, or addition of antibodies at the time of assay, blocked over $95 \%$ of
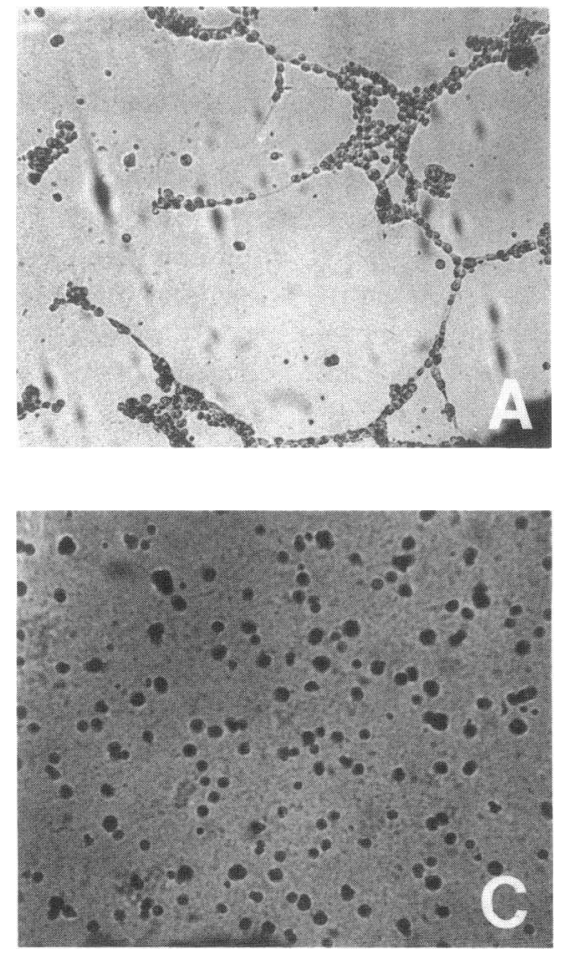
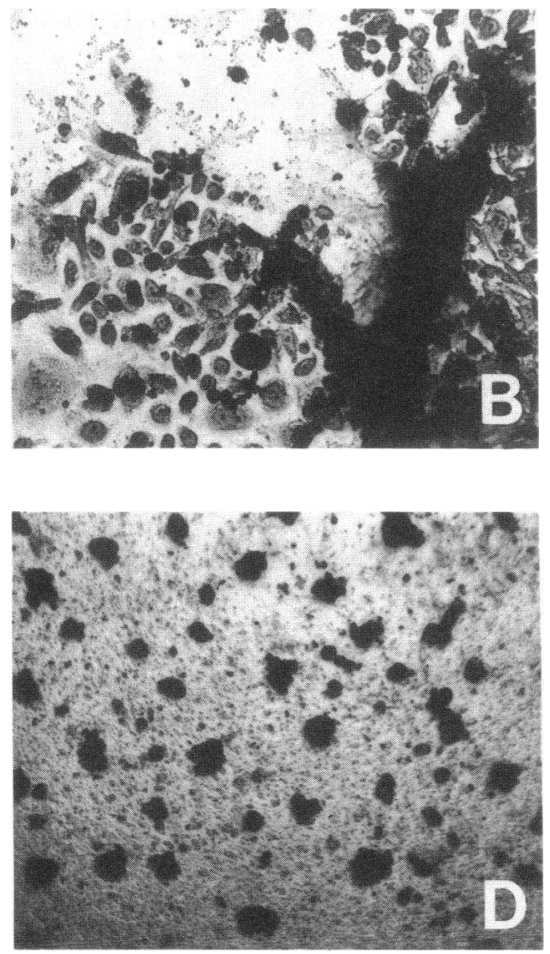

Figure 4. PC3 growth on matrigel. Cells pretreated for $4 \mathrm{~d}$ with $5 \mathrm{mM} \mathrm{NaPA}$ were replated onto dishes coated with matrigel. $(A)$ Pictures of controls, taken the following day, show formation of netlike structures characteristic of malignant PC3 cells. $(B) 7 \mathrm{~d}$ later, these cells degraded the matrigel barrier and formed monolayers on the plastic surface beneath. In a marked contrast, NaPA-treated PC 3 failed to form "nets" $(C$, day 1$)$ and developed isolated small colonies incapable of matrigel degradation ( $D$, taken $8 \mathrm{~d}$ after plating). The behavior of treated PC 3 cells resembled that of normal human FS4 cells. 
Table I. Tumorigenicity of Prostatic PC3 Cells in Nude Mice

\begin{tabular}{lccc}
\hline & \multicolumn{3}{c}{ Tumors } \\
\cline { 2 - 4 } Treatment & Incidence & $\begin{array}{c}\text { Diameter } \\
( \pm \mathrm{SD})\end{array}$ & $\begin{array}{c}\text { Weight } \\
( \pm \text { SD) }\end{array}$ \\
\hline & & $m m$ & $m g$ \\
None & $7 / 7$ & $9 \pm 3$ & $285 \pm 60$ \\
NaPA & $1 / 7$ & 2 & 50 \\
PAG & $3 / 4$ & $8 \pm 2$ & $245 \pm 35$
\end{tabular}

Cells were pretreated for one week with $5 \mathrm{mM}$ of either NaPA or PAG before being injected $\left(5 \times 10^{5}\right.$ cells per animal) subcutaneously into athymic mice. Results indicate tumor incidence (tumor bearing/injected animals), size, and weight (mean $\pm \mathrm{SD})$, as determined $8 \mathrm{wk}$ after cell transplantation.

the plasminogen-dependent proteolytic activity. Plasminogenindependent proteolysis constituted $\sim 30 \%$ of the maximal fibronectin degrading activity, and was similar for both NaPAtreated cells and untreated controls.

Potentiation of suramin antitumor activity. The diversity in therapeutic responses of heterogeneous tumor masses calls for design of appropriate combination treatment protocols. Sura$\min$ is an experimental drug active in patients with advanced prostatic cancer; however, drug toxicities have been a major concern. In agreement with previous in vitro studies (44), we found that toxic doses of suramin $(300 \mu \mathrm{g} / \mathrm{ml})$ were needed in order to achieve over $50 \%$ inhibition of prostatic DU145 cell growth. This cellular model was used to examine whether NaPA could enhance the activity of suboptimal but less toxic doses of suramin. Results summarized in Fig. $6 \mathrm{~A}$ show that $\mathrm{NaPA}$ and suramin act in an additive manner to inhibit DU145 cell proliferation. Moreover, suramin was found to be significantly more active if added to glutamine-depleted medium (Fig. $6 \mathrm{~B}$ ). Despite significant differences in tumor sensitivities, there was complete growth arrest when DU145 and PC 3 cells were treated for $6 \mathrm{~d}$ with both NaPA and suramin in glutamine-depleted medium, under conditions in which each treatment alone had only a partial effect.

\section{Discussion}

In 1991, prostate cancer claimed the lives of more than 30,000 men in the United States alone. This grim statistic reflects on

\section{3}

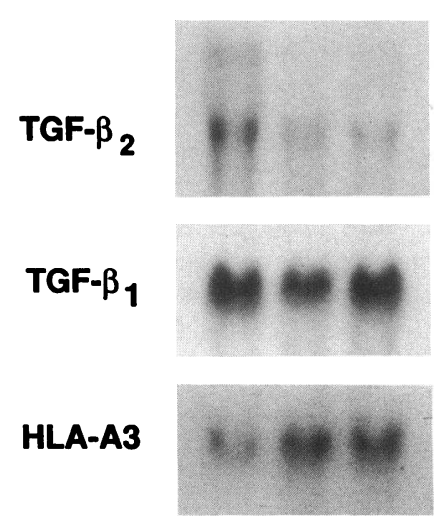

Figure 5. Alterations in gene expression. Northern blot analysis of cytoplasmic RNA isolated from control PC3 (lane 1) and cells treated for $72 \mathrm{~h}$ with $\mathrm{NaPA}, 5$ and $7.5 \mathrm{mM}$ (lanes 2 and 3 , respectively). The blot was reprobed sequentially with the indicated cDNA probes. RNA in lane 2 was slightly underloaded, as indicated by the relative amounts of ribosomal RNA observed after staining with ethidium bromide (not shown).
Table II. Modulation of uPA Activity

\begin{tabular}{lllc}
\hline Cells & NaPA & \multicolumn{1}{c}{ uPA* $^{*}$} & Inhibition \\
\hline & $m M$ & $P U / 10^{6}$ cells & $\%$ \\
PC3-1 & 0 & $2.21 \pm 0.23$ & - \\
& 2.5 & $1.48 \pm 0.16$ & 33.1 \\
& 5 & $0.89 \pm 0.12$ & 59.7 \\
& 7.5 & $0.66 \pm 0.04$ & 70.2 \\
DU145 & $7.5 \rightarrow$ off $^{\ddagger}$ & $2.26 \pm 0.1$ & 0 \\
& 0 & $2.75 \pm 0.30$ & - \\
LNCaP & 5 & $1.47 \pm 0.09$ & 46.4 \\
& 0 & $<0.3$ & - \\
\hline
\end{tabular}

* Cell-associated uPA activity was determined by the ability of intact cells to degrade fibronectin in the presence of plasminogen.

₹ Cells were treated with NaPA for $4 \mathrm{~d}$ and then cultured in the absence of drug for additional $3 \mathrm{~d}$ to determine the stability of effect. In all other cases, cells were treated continuously for 3-4 d until assay. UPA activity of untreated cells is shown for comparison.

the high disease incidence and the poor response to conventional therapies. The data presented here points to the differentiation inducer, sodium phenylacetate, as a potential candidate for treatment of advanced disease.

By using tumor cell lines as a model (PC3, DU145, and LNCaP), it was demonstrated that NaPA can suppress the proliferation of metastatic human prostate cells and promote their reversion to a nonmalignant phenotype. Within $1 \mathrm{wk}$ of treatment in culture, the malignant cells have lost the ability to invade reconstituted basement membranes (matrigel) and to form rapidly growing tumors in recipient athymic mice. The latter was associated with changes in expression of genes implicated in tumor growth and invasion, immunogenicity, and angiogenesis (see below). The concentrations of PA producing significant antitumor effects in vitro, although high (1-6 mM), have been achieved in humans with no significant adverse effects $(15,16)$. Consistent with this finding, PA inhibited cancerous growth in the laboratory while sparing actively replicating normal human endothelial cells and skin fibroblasts. Remarkably, similar selective effects have been observed in plants, where phenylacetate is one of several growth regulators (auxins) known to inhibit cell proliferation at millimolar concentrations, affecting the least-differentiated plant tumor cells more than normal tissues (45). It appears therefore that PA-selective antitumor activity may have been conserved in evolution.

The mechanisms of NaPA antitumor activity are not known. Its best characterized activity in humans is the ability to conjugate to, and deplete circulating glutamine, the aminoacid on which tumor cells depend for fuel and macromolecular biosynthesis. Glutamine starvation alone (achieved by growing cells in glutamine-depleted medium) was sufficient to selectively suppress the growth of prostatic cells in vitro. The promise of anti-glutamine therapy was demonstrated in the clinic with the glutamine antimetabolites DON and acivicin, and the glutamine-depleting enzyme glutaminase. Unfortunately, DON and acivicin treatments have been associated with toxicities attributed to irreversible inhibition of glutamine aminotransferases involved in the de novo synthesis of purine and pyrimidines (23). Glutaminase treatment, on the other hand, 
A

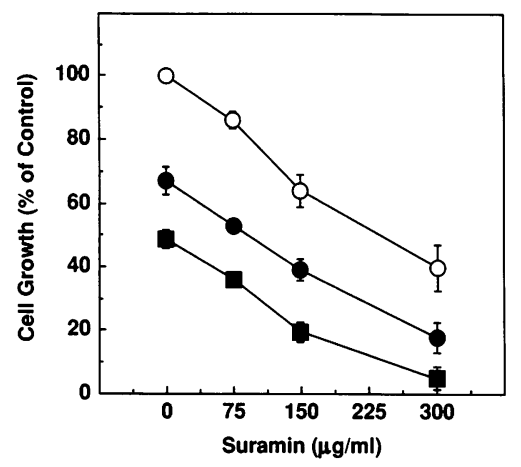

B

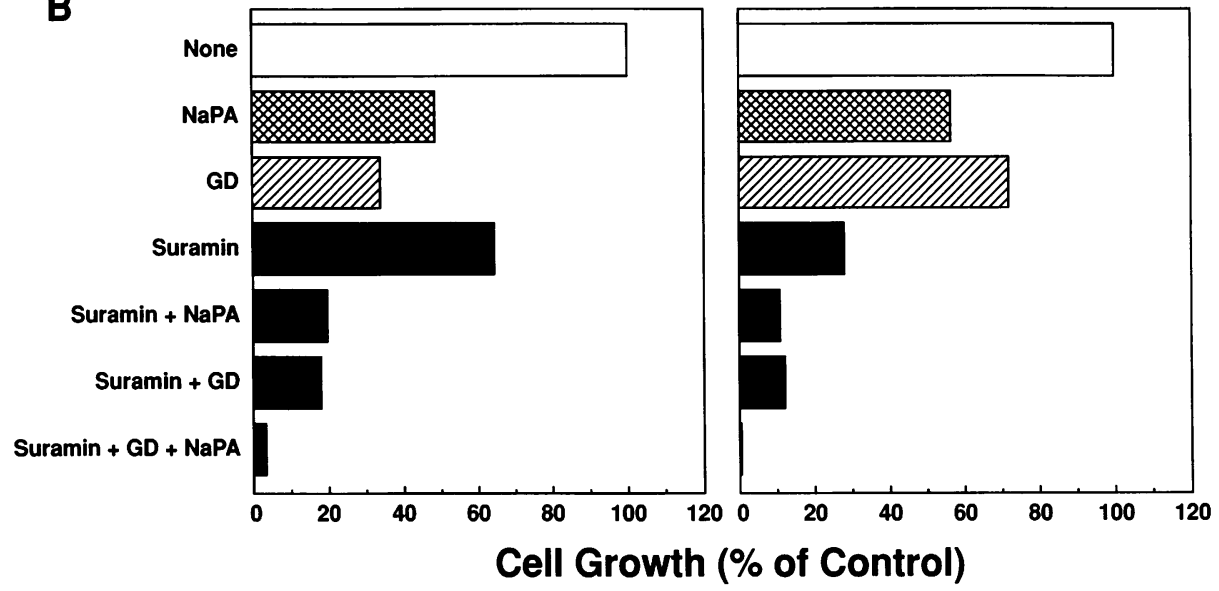

Figure 6. Potentiation of suramin activity by NaPA. $(A)$ DU145 cultures were treated for $5 \mathrm{~d}$ with different doses of suramin, used alone $(O)$ or in combination with NaPA $2.5 \mathrm{mM}(\bullet)$ and $5 \mathrm{mM}(\bullet)$. Data represent means $\pm \operatorname{SD}(n=3)$. (B) To mimic hypothetical in vivo conditions (see text), prostatic DU145 (left panel) and PC3 (right panel) were exposed to both NaPA $5 \mathrm{mM}$ and suramin $150 \mu \mathrm{g} / \mathrm{ml}$ in glutamine-depleted medium (GD, $0.2 \mathrm{mM}$ glutamine). The results, shown in the lower histogram, indicate almost complete growth arrest of either cell line, despite differences in responses to each treatment alone. Significant cytotoxicity (over $20 \%$ ) was observed only in cases involving suramin $300 \mu \mathrm{g} / \mathrm{ml}$.

is restricted by rapid production of neutralizing antibodies to this bacterial enzyme, or the development of hypersensitivity reactions $(26,27)$. PA, a naturally occurring plasma component with no known effect on glutamine utilizing enzymes, may have advantages over the other approaches to glutamine depletion, in as much as it could reduce the levels of plasma glutamine to affect tumor growth with minimal toxicities to the host. While glutamine depletion may play a role in vivo, some of our experimental data could not be explained by an effect on glutamine metabolism, suggesting the involvement of additional mechanisms. First, the enzymatic reaction leading to glutamine depletion takes place in the mitochondria of human liver and kidney cells (22), but may not occur in the tumor cell line treated in vitro (15). Second, glutamine conjugation by PA is species-specific and limited to humans and high primates, yet the drug can induce differentiation in mouse cells at high efficiency (13). Third, cell maturation induced by PA could not be mimicked by glutamine depletion alone or by treatment with the antiglutamine drugs, DON and acivicin (data presented here and in reference 13). We speculate therefore that, in humans, PA could potentially arrest tumor growth through depletion of circulating glutamine and additional celldirected effect(s) not yet identified.

One hypothesis currently being tested is that tumor suppression by NaPA may be due in part to inhibition of DNA methylation (reference 46, and our unpublished data), an epigenetic mechanism implicated in the control of gene expression and cell phenotype. Hypomethylation can lead to tumor differentiation, but it can also promote neoplastic transformation and the evolution of cells with metastatic capabilities (34). Studies comparing NaPA with the hypomethylating chemotherapeutic drug 5-aza-2'-deoxycytidine, revealed that phenylacetate, unlike the cytidine analogue, does not cause neoplastic transformation in susceptible cells (13). In addition to DNA methylation, NaPA may affect also lipid metabolism. In cells, PA is converted to phenylacetyl-CoA, which can replace acetyl-CoA as a primer for fatty acid synthetase reactions (47). This could lead to synthesis of abnormal lipids and inhibition of lipogenic enzymes. We noted abnormal accumulation of lipids in several responsive tumor cell lines derived from patients with prostatic carcinoma ( see Fig. 2), glioblastoma, and malignant melanoma (unpublished). The composition and biological significance of these lipids are yet to be determined.

Preliminary molecular analysis of NaPA-treated prostatic tumor cells revealed changes in the expression of several genes, including reduction in TGF- $\beta 2$ mRNA levels. The TGF- $\beta$ gene family is thought to affect cell proliferation, and facilitate tumor-induced immunosuppression and angiogenesis $(40,41)$. TGF- $\beta$ can suppress both cellular and humoral immunity, decrease interferon production, and down-regulate HLA antigen presentation by tumor cells. The decline in TGF- $\beta 2$ was accompanied by increased expression HLA-A3, coding for class I major histocompatibility antigen, which could enhance tumor immunogenicity in vivo (48). Although further studies are needed to determine protein levels and biological activity, it is interesting to note that cells treated in vitro failed to grow in athymic mice with active cellular immunity, or formed small, noninvasive nodules with poor vasculature.

Reduced invasive capacity may be due in part to NaPA effect on tumor-associated uPA activity. uPA is a key enzyme involved in proteolytic reactions leading to tumor invasion and metastasis ( reviewed in references 42 and 43 ). uPA can control localized tissue proteolysis by converting the inactive zymogen plasminogen into plasmin. Plasmin, in turn, is a multipotent proteolytic enzyme capable of degrading extracellular matrix and basement membrane components by a direct effect on fibronectin, laminin, proteoglycans, and some collagens, as well as through activation of latent metalloproteases (e.g., collagenase type IV and stromelysin). Alterations in uPA have been documented in several cancers, including prostate (49-52) breast (53), and gastrointestinal tract (54). In prostatic carcinoma, increased activity of autocrine, receptor-bound uPA has been associated with cell proliferation, migration, invasion, and metastasis $(38,39,49)$. Analysis of tumor cell lines and surgical specimen showed higher amounts of uPA in metastatic prostate lesions compared to corresponding primary tumors or benign hyperplastic tissues $(48,49)$. In fact, plasma levels of uPA in prostate cancer patients proved to be a reliable marker 
for the presence of bone metastases, with a better sensitivity $(80 \%)$ than alkaline phosphatase $(51,52)$. Regulation of uPA activity is complex, involving synthesis of pro-uPA, its receptor, activators, and specific inhibitors $(42,43)$. Other differentiating agents such as retinoic acid and sodium butyrate, reduce uPA activity by inhibiting the proenzyme production $(55,56)$. The molecular level and mechanisms by which NaPA affects uPA and other genes are under investigation.

It appears therefore that the differentiation inducer, PA, could modify the biology of metastatic prostate cells at drug doses that are neither cytotoxic nor carcinogenic. It is possible that phenylacetate, like other cytostatic drugs (e.g., hormoneantagonists), would have to be administered continuously in order to maximize efficacy. Any attempt, however, to eradicate the heterogeneous cell population of a tumor mass would require the use of appropriate combination treatment protocols (57). NaPA was found to potentiate the in vitro antitumor activity of suramin, a cytostatic drug acting through different mechanisms, including growth factor antagonism $(4,5)$ and disruption of cellular energy balance (58). Suramin is one of a few agents shown to benefit patients with hormone-refractory prostate carcinoma (5); however, its clinical usefulness has been hindered by toxicities associated with high plasma levels (over $250 \mu \mathrm{g} / \mathrm{ml}$ ). Our data suggest that tumor responses may be achieved with significantly lower doses of suramin if combined with PA. A well-tolerated drug like NaPA could subsequently be administered chronically to maintain responses and prevent disease relapse. NaPA, which has an unpleasant odor, can be substituted by sodium phenylbutyrate for oral administration (upon ingestion by humans, phenylbutyrate undergoes $\beta$-oxidation to PA [ 59]). The antitumor activity, easy administration, and lack of significant adverse effects make PA and its pro-drug, phenylbutyrate, attractive candidates for clinical use in treatment of advanced prostatic cancer and possibly other human malignancies as well.

\section{Acknowledgments}

We thank V. Sykes for outstanding technical assistance and V. Cioce for help with molecular analysis.

This study was supported by Elan Pharmaceutical Corporation grant G174ED.

\section{References}

1. Chiarodo, A. 1991. National Cancer Institute Roundtable on Prostate Cancer: future research directions. Cancer Res. 51:2498-2505. 245

2. Gittes, R. F. 1991. Carcinoma of the prostate. N. Engl. J. Med. 324:236-

3. Eisenberger, M. A. 1992. Chemotherapy for endocrine resistant cancer of the prostate. Prog. Clin. Biol. Res. 359:155-164; discussion 177-180.

4. Myers, C. E., R. LaRocca, M. Cooper, R. Danesi, C. A. Jamis-Dow, C. A. Stein, and M. W. Linehan. 1991. Role of suramin in cancer biology and treatment. In Molecular Foundation of Oncology. S. Broder, editor. Williams \& Wilkins Co., Baltimore, MD. 419-434.

5. Myers, C. E., C. S. Stein, M. Cooper, R. LaRocca, M. C. Walter, G. Weiss, P. Choyke, G. Chrousos, N. Dawson, S. Steinberg, et al. 1992. Suramin: a novel growth factor antagonist with activity in hormone-refractory metastatic prostate cancer. J. Clin. Oncol. 10:881-889.

6. Keating, M. T., J. A. Escobedo, and L. T. Williams. 1988. Ligand activation causes a phosphorylation-dependent change in platelet-derived growth factor receptor conformation. J. Biol. Chem. 263:12805-12808.

7. Sacks, L. 1978. Control of normal cell differentiation and the phenotypic reversion of malignancy in myeloid leukemia. Nature (Lond.). 274:535-539.

8. Bloch, A. 1984. Induced cell differentiation in cancer therapy. Cancer Treat. Rep. 68:199-205.
9. Samid, D., D. M. Flessate, and R. M. Friedman. 1987. Interferon-induced revertants of ras-transformed cells: resistance to transformation by specific oncogenes and retransformation by 5-azacytidine. Mol. Cell. Biol. 7:2196-2200.

10. Golomb, H. M., M. J. Ratain, R. Mick, and K. Daly. 1992. The treatment of hairy cell leukemia: an update. Leukemia. 6(Suppl.2):24-27.

11. Momparler, R. L., G. E. Rivard, and M. Gyger. 1985. Clinical trial on 5-aza-2'-deoxycytidine in patients with acute leukemia. Pharmacol. Ther. 30:277-286.

12. Muindi, J. R., S. R. Frankel, C. Huselton, F. DeGrazia, W. A. Garland, C. W. Young, and R. P. Warrell, Jr. 1992. Clinical pharmacology of oral all-trans retinoic acid in patients with acute promyelocytic leukemia. Cancer Res. 52:2138-2142.

13. Samid, D., S. Shack, and L. T. Sherman. 1992. Phenylacetate: a novel nontoxic inducer of tumor cell differentiation. Cancer Res. 52:1988-1992.

14. Samid, D., A. Yeh, and P. Prasanna. 1992. Induction of erythroid differentiation and fetal hemoglobin production in human leukemic cells treated with phenylacetate. Blood. 80:1576-1581.

15. Brusilow, S. W., M. Danney, L. J. Waber, M. Batshaw, B. Burton, L. Levitsky, K. Roth, C. McKeethren, and J. Ward. 1984. Treatment of episodic hyperammonemia in children with inborn errors of urea synthesis. $N$. Engl. J. Med. 310:1630-1634.

16. Simell, O., I. Sipila, J. Rajantie, D. L. Valle, and S. W. Brusilow. 1986 Waste nitrogen excretion via amino acid acylation: benzoate and phenylacetate in lysinuric protein intolerance. Pediatr. Res. 20:1117-1121.

17. Dover, G. J., S. Brusilow, and D. Samid. 1992. Increased fetal hemoglobin in patients receiving sodium 4-phenylbutyrate. N. Engl. J. Med. 327:569-570.

18. Nuti, M. P., M. De Bertoldi, and A. A. Lepidi. 1972. Influence of phenylacetic acid on poly- $\beta$-hydroxybutyrate polymerization and cell elongation in $A s o-$ bacter chroococcum Beij. Can. J. Microbiol. 18:1257-1261.

19. Kishore, G., M. Sugumaran, and C. S. Vaidyanathan. 1976. Metabolism of DL-phenylalanine by Aspergillus niger. J. Bacteriol. 128:182-191.

20. Wightman, F., and D. L. Lighty. 1982. Identification of phenylacetic acid as a natural auxin in the shoots of higher plants. Physiol. Plant. 55:17-24.

21. Scheidt, S. 1990. Angina: evolution of the role of nitrates. Am. Heart J. 120:757-761; discussion 769-772.

22. James, M. O., R. L. Smith, F. R. S. Williams, R. T., and M. Reidenberg 1972. The conjugation of phenylacetic acid in man, sub-human primates and some non-primate species. Proc. R. Soc. Lond. B. Biol. Sci. 182:25-35.

23. Weber, G. 1983. Biochemical strategy of cancer cells and the design of chemotherapy: G. H. A. Clowes Memorial Lecture. Cancer Res. 43:3466-3492.

24. Medina, M. A., F. Sanchez-Jimenez, F. J. Marquez, J. Perez-Rodriguez, A. R. Quesada, and I. Nunez de Castro. 1988. Glutamine and glucose as energy substrates for ehrlich ascites tumor cells. Biochem. Int. 16:339-347.

25. Rosenfeld, H., and J. Roberts. 1981. Enhancement of antitumor activity of glutamine antagonists 6-diazo-5-oxo-l-norleucine and acivicin in cell culture by glutaminase-asparaginase. Cancer Res. 41:1324-1328.

26. Holcenberg, J. 1981. Enzyme therapy of cancer, future studies. Cancer Treat. Rep. 65(Suppl. 4):61-71.

27. Roberts, J., J. S. Holcenberg, and W. C. Dolowy. 1970. Antineoplastic activity of highly purified bacterial glutaminase. Nature (Lond.). 227:1136-1137.

28. Kaighn, M. E., J. F. Lechner, K. S. Narayan, and L. W. Jones. 1978. Prostate carcinoma: tissue culture cell lines. Natl. Cancer Inst. Monogr. 49:17-21.

29. Stone, K. R., D. D. Mickey, H. Wunderli, G. H. Mickey, and D. F. Paulson. 1978. Isolation of a human prostate carcinoma cell line (DU 145). Int. J. Cancer. 21:274-281.

30. Horoszeweiz, J. S., S. S. Leong, T. Ming-Chu, Z. L. Wajsman, M. Friedman, L. Papsidero, U. Kim, L. S. Chai, S. Kakati, S. K. Arya, et al. 1980. The LNCaP cell line-a new model for studies on human prostatic carcinoma. Prog. Clin. Biol. Res. 37:115-132.

31. Grant, D. S., P. I. Lelkes, K. Fukuda, and H. Kleinman. 1990. Intracellular mechanisms involved in basement membrane induced blood vessels differentiation in vitro. In Vitro Cell. Dev. Biol. 27A:327-336.

32. Albini, A., Y. Iwamoto, H. K. Kleinman, G. R. Martin, S. A. Aaronson, J. M. Kozlowski, and R. N. McEwan. 1987. A rapid in vitro assay for quantitating the invasive potential of tumor cells. Cancer Res. 47:3239-3245.

33. Mandler, R., D. Rimoldi, K. Kariko, and D. Samid. 1991. Urokinase-type plasminogen activator in experimental metastasis of human osteosarcoma cells. Cancer J. 4:316-321.

34. Rimoldi, D., V. Srikantan, V. L. Wilson, R. H. Bassin, and D. Samid. 1991. Increased sensitivity of nontumorigenic fibroblasts expressing ras or myc oncogenes to malignant transformation induced by 5-aza-2'-deoxycytidine. Cancer Res. 51:1-7.

35. Cowan, E. P., B. R. Jordan, and J. E. Coligan. 1985. Molecular cloning and DNA sequence analysis of genes encoding cytotoxic $T$ lymphocyte-defined HLA-A3 subtypes: the E1 subtype. J. Immunol. 135:2835-2841.

36. Quian, S. W., P. Kondaiah, W. Casscells, A. B. Roberts, and M. B. Sporn. 1991. A second messenger RNA species of transforming growth factor beta 1 in infarcted rat heart. Cell. Regul. 2:241-249.

37. Hanks, S. K., R. Armour, J. H. Baldwin, F. Maldonado, J. Spiess, and R. W. Holley. 1988. Amino acid sequence of the BSC-1 cell growth inhibitor 
(polyergin) deduced from the nucleotide sequence of the cDNA. Proc. Natl. Acad. Sci. USA. 85:79-82.

38. Hoosein, N. M., D. D. Boyd, W. J. Hollas, A. Mazar, J. Henkin, and L. W. K. Chung. 1991. Involvement of urokinase and its receptor in the invasiveness of human prostatic carcinoma cell lines. Cancer Commun. 3:255-264.

39. Gaylis, F. D., H. N. Keer, M. J. Wilson, H. C. Kwaan, A. A. Sinha, and J. M. Kozlowski. 1989. Plasminogen activators in human prostate cancer cell lines and tumors: correlation with the aggressive phenotype. J. Urol. 142:193198.

40. Maxwell, M., T. Galanopoulos, J. Neville-Golden, and H. N. Antoniades. 1992. Effect of the expression of transforming growth factor-beta2 in primary human glioblastomas on immunosuppression and loss of immune surveillance. J. Neurosurg. 76:799-804.

41. Roberts, A. B., M. B. Sporn, R. K. Assoian, J. M. Smith, N. S. Roche, L. M. Warefield, V. I. Heine, L. A. Liotta, V. Falanga, J. H. Kehrl, et al. 1986. Transforming growth type beta: rapid induction of fibrosis and angiogenesis in vivo and stimulation of collagen formation in vitro. Proc. Natl. Acad. Sci. USA. 83:4167-71.

42. Testa, J. E., and J. P. Quigley. 1990. The role of urokinase-type plasminogen activator in aggressive tumor cell behavior. Cancer Metastasis Rev. 9:353367.

43. Blasi, F., and P. Verde. 1990. Urokinase-dependent cell surface proteolysis and cancer. Cancer Biol. 1:117-126.

44. LaRocca, R. V., R. Danesi, M. R. Cooper, C. A. Jamis-Dow, M. W. Ewing, W. M. Linehan, and C. E. Myers. 1991. Effect of suramin on human prostate cancer cells in vitro. $J$. Urol. 145:393-398.

45. De Ropp, R. S. 1947. The response of normal plant tissue and of crowngall tumor tissues to synthetic growth hormones. Am. J. Bot. 34:53-62.

46. Vanjusin, B. F., E. A. Bashkite, A. Friedrich, and L. Chvojka. 1981. Metilirovanie DNK $\vee$ porostkach psenicy i vlijanije fytogormonov (in Russ.). Biokhimiya 1. 46:47-53.

47. Smith, S., and A. Stern. 1983. The effect of aromatic coA esters on fatty acid synthetase: biosynthesis of $\omega$-phenyl fatty acids. Arch. Biochem. Biophys. 222:259-265

48. Redondo, M., A. Concha, R. Oldiviela, A. Cueto, A. Gonzalez, F. Garrido, and F. Ruiz-Cabello. 1991. Expression of HLA class I and II antigens in bronchogenic carcinomas: its relationship to cellular DNA content and clinicalpathological parameters. Cancer Res. 51:4948-4954.

49. Camiolo, S. M., G. Markus, L. S. Englander, M. R. Siuta, G. H. Hobika and S. Kohga. 1984. Plasminogen activator content and secretion in explants of neoplastic and benign human prostate tissues. Cancer Res. 44:311-318.

50. Kirchheimer, J. C., H. Pfluger, P. Ritschl, G. Hienert, and B. R. Binder. 1985. Plasminogen activator activity in bone metastases of prostatic carcinomas as compared to primary tumors. Invasion Metastasis. 5:344-355.

51. Hienert, G., J. C. Kirchheimer, H. Pfluger, and B. R. Binder. 1988. Urokinase-type plasminogen activator as a marker for the formation of distant metastases in prostatic carcinomas. J. Urol. 140:1466-1469.

52. Hienert, G., J. C. Kirchheimer, G. Christ, H. Pfluger, and B. R. Binder 1988. Plasma urokinase-type plasminogen activator correlates to bone scintigraphy in prostatic carcinoma. Eur. Urol. 15:256-258.

53. Duffy, M. J., D. Reilly, C. O'Sullivan, N. O'Higgins, J. J. Fennelly, and P. Andreasen. 1990. Urokinase plasminogen activator, a new and independent prognostic marker in breast cancer. Cancer Res. 50:6827-6829.

54. De Bruin, P. A., H. W. Verspaget, G. Griffioen, J. H. Verheijen, D. Dooijeward, and C. B. H. W. Lamers. 1989. Plasminogen activators in endoscopic biopsies as indicators of gastrointestinal cancer: comparison with resection specimens. Br. J. Cancer. 60:397-400.

55. Gross, J. L., D. L. Behrens, D. E. Mullins, P. L. Kornblith, and D. L. Dexter. 1988. Plasminogen activator and inhibitor activity in human glioma cells and modulation by sodium butyrate. Cancer Res. 48:291-296.

56. Prager, M. D., N. F. Nelson, W. Cieplak, and S. C. Dacus. 1986. Characterization of plasminogen-activator from two human renal-carcinoma cell-lines and effect of differentiation inducing agents. Proc. Am. Assoc. Cancer Res. 27:3. (Abstr.)

57. Heppner, G. H., and B. Miller. 1983. Tumor heterogeneity; biological implications and therapeutic consequences. Cancer Metastasis Rev. 2:5-23.

58. Rago, R., J. Mitchen, A-L. Cheng, T. Oberley, and G. Wilding. 1991. Disruption of cellular energy balance by suramine in intact human prostatic carcinoma cells, a likely antiproliferative mechanism. Cancer Res. 51:66296635 .

59. Knoop, F. 1905. Der Abbau aromatischer fettsaüre Tierkorper. Beitr. Chem. Physiol. Pathol. 6:150-162. 